Please do not remove this page

RMIT

UNIVERSITY

\title{
Ultrathin Solar Absorber Layers of Silver Bismuth Sulfide from Molecular Precursors
}

van Embden, Joel; Della Gaspera, Enrico

https://researchrepository.rmit.edu.au/esploro/outputs/9921860828201341/filesAndLinks?institution=61RMIT_INST\&index=null

Van Embden, J., \& Della Gaspera, E. (2019). Ultrathin Solar Absorber Layers of Silver Bismuth Sulfide from Molecular Precursors. ACS Applied Materials and Interfaces, 11(18), 16674-16682.

https://doi.org/10.1021/acsami.8b22414

Document Version: Accepted Manuscript

Published Version: https://doi.org/10.1021/acsami.8b22414

Repository homepage: https://researchrepository.rmit.edu.au

(c) 2019 American Chemical Society.

Downloaded On 2023/04/26 20:23:58 +1000

Please do not remove this page 


\section{Ultra-Thin Absorber Layers of Silver Bismuth}

\section{Sulfide from Molecular Precursors}

Joel van Embden ${ }^{1, *}$, Enrico Della Gaspera, ${ }^{1, *}$

${ }^{1}$ School of Science, RMIT University, Melbourne VIC 3000, Australia

KEYWORDS: AgBiS2, silver, bismuth, thin film, solar 


\section{ABSTRACT}

Here we present a robust molecular precursor-based approach to synthesize high quality thin films of silver bismuth sulfide $\left(\mathrm{AgBiS}_{2}\right)$. Pure phase cubic $\mathrm{AgBiS}_{2}$ thin films are prepared, which are smooth and dense down to thicknesses less than $40 \mathrm{~nm}$. Comprehensive structural and morphological analysis of the as-prepared films as a function of processing temperature and composition is presented, including X-ray diffraction, X-ray photoelectron spectroscopy and Scanning Electron Microscopy. The optical properties of the films and their electronic band structure are also presented. The as-prepared films showing impressive light absorption properties with absorption coefficients reaching $10^{5} \mathrm{~cm}^{-1}$ for energies above c.a. $950 \mathrm{~nm}$. Finally, their photoactivity is demonstrated through photoconductivity measurements on lateral electrodes. The methods outlined herein enable the fabrication of $\mathrm{AgBiS}_{2}$ semiconductor thin films at low processing temperatures $\left(150{ }^{\circ} \mathrm{C}\right)$ with a dense morphology and tunable $\mathrm{Ag}: \mathrm{Bi}$ composition. Such films provide an excellent platform for the fabrication of $\mathrm{AgBiS}_{2}$-based optoelectronic devices and solar cells. 


\section{INTRODUCTION}

Solution processing is a powerful and versatile approach for achieving thin film materials with tailored composition, morphology and functional properties. ${ }^{1,2,3,4,5,6}$ As such, it has been widely investigated for myriad applications, including sensing, catalysis, optoelectronics, energy

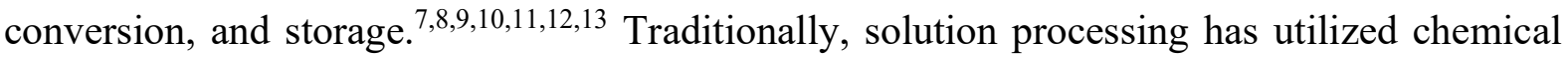
bath deposition and electrochemical deposition. ${ }^{14,15,16,17,18}$ Colloidal nanocrystal (NC) have also been extensively used, wherein the desired NCs are first synthesized and subsequently formulated into an "ink" suitable for thin film deposition ${ }^{8,19,20,21,22,23}$ Recently, research in the area of solution processed thin films has received increasing focus on the use of molecular metal-organic complexes, termed molecular precursors (MP). The MP approach entails the formulation of a solution containing discrete precursors that can be readily cast into a thin film and then decompose upon heating to form the desired compound and crystal phase. ${ }^{24,25}$

During its inception, the field of MPs was mainly focused on metal oxides, with sol-gel approaches having been used for decades for the fabrication of thin films and porous materials for a variety of applications. ${ }^{26,27,28}$ In recent years, molecular precursors have been extended to the synthesis of semiconducting chalcogenide materials, especially metal sulfides. For example, the Mitzi et. al pioneered the use of hydrazine as a solvent to dissolve simple metal chalcogenides for the synthesis of $\mathrm{Cu}_{2} \mathrm{ZnSnS}_{4}$ (CZTS) thin films. ${ }^{5}$ An alternative method by the group of Hillhouse investigated metal-thiourea complexes in coordinating solvents such as DMSO for the synthesis of a variety of sulfides, including CZTS and $\mathrm{CuIn}_{\mathrm{x}} \mathrm{Ga}_{(1-\mathrm{x})} \mathrm{S}_{2}$ (CIGS). ${ }^{29}$ The group of Brutchey developed a solvent mixture based on ethylenediamine and short-chain thiols able to dissolve a large variety of metal salts, which was then used to deposit thin films that convert to pure metal chalcogenides upon heating. ${ }^{30}$ Additional approaches have also been proposed, showing the large potential of molecular precursors for the synthesis of a wide range of semiconducting materials. ${ }^{31,32}$ 
To frame the current work, we note that the current competitive approach to the use of MPs is colloidal nanocrystal (NC) inks. The MP and NC approaches have both advantages and disadvantages. Through surface engineering, NC inks typically have lower organic:inorganic ratios compared to their MP analogues and offer greater control over crystal domain size and shape. However, this comes at the cost of a longer, more complex synthetic processes (for both nanocrystal synthesis and ink formulation), great difficulty with scale-up, and in the case of ternary and quaternary NCs, poor or no control over the final crystal composition. ${ }^{33}$ Molecular precursor strategies are more versatile and flexible, enabling access to a wider range of materials (including those yet to be successfully synthesized as nanocrystals), and at the same time involve simpler scalable synthetic processes with highly accurate compositional control. Recent progress in the field has shown that materials of the highest quality can be fabricated from MPs, laying the foundation for the adoption of such precursors for the manufacture of efficient devices. $^{7,29}$

Over the past few years the material silver bismuth sulfide $\left(\mathrm{AgBiS}_{2}\right)$ has received renewed attention as an absorber layer for photovoltaic applications, with extremely promising initial results. ${ }^{34,35,36,37} \mathrm{AgBiS}_{2}$ is a I-III-VI $\mathrm{VI}_{2}$ semiconductor comprised of non-toxic elements with desirable optoelectronic properties, including a narrow band gap at around 1.1-1.2 eV and a large absorption coefficient $\left(\sim 10^{5} \mathrm{~cm}^{-1}\right.$ in the visible spectral range).$^{38,39}$ Prior work on $\mathrm{AgBiS}_{2}$ includes the solid-state synthesis of single crystal ingots, sequential ionic layer adsorption reaction (SILAR) techniques, solvothermal methods, microwave synthesis and colloidal nanocrystals. . $^{34,40,41,42,35,36,39,43}$

To date there exists only a single work (from the Brabec group) demonstrating the fabrication of $\mathrm{AgBiS}_{2}$ thin films through the use of MPs. ${ }^{38}$ We note here that the thiourea method outlined therein was shown to be limited to fabrication temperatures above $250{ }^{\circ} \mathrm{C}$ and film thickness above $200 \mathrm{~nm}$. Importantly, prior investigations into the fabrication of solar cells 
from both spin-coated and spray coated $\mathrm{AgBiS}_{2}$ nanocrystal-based solutions has revealed that low processing temperatures $\left(100-150^{\circ} \mathrm{C}\right)$ and films with thickness below c.a. $60 \mathrm{~nm}$ are critical to achieving high performing solar cell devices. ${ }^{36,35,37,44}$ While the optimized thin films from the aforementioned thiourea-based precursors display excellent qualities, the required processing conditions fall clearly outside of these optimal film and processing parameters for $\mathrm{AgBiS}_{2}$. This raises legitimate concern as to the flexibility and suitability of such methods for generating thin films appropriate for device incorporation. In light of these current limitations, it remains highly desirable to develop alternative methods to $\mathrm{AgBiS}_{2} \mathrm{NCs}$ that are able to produce device quality ultra-thin films at low processing temperatures.

Here we report for the first time a robust and reproducible MP approach to synthesize high (device) quality thin films of $\mathrm{AgBiS}_{2}$ with tunable thicknesses to below $40 \mathrm{~nm}$. Metaldithiocarbamate (DTC) complexes of silver and bismuth were synthesized and used to fabricate $\mathrm{AgBiS}_{2}$ thin films via spin coating. Our approach leverages off the low decomposition temperatures of metal-DTC complexes and circumvents the need for the prior synthesis of $\mathrm{AgBiS}_{2} \mathrm{NCs}$, while providing accurate control over Ag:Bi stoichiometry, retaining excellent tunability of film thickness, and access to processing temperatures as low as $150{ }^{\circ} \mathrm{C}$.

Comprehensive structural and morphological analyses of the as-prepared films as a function of both processing temperature and $\mathrm{Ag}$ :Bi composition are presented, including X-ray diffraction, X-ray photoelectron spectroscopy and Scanning Electron Microscopy. The optical properties of the films and their electronic band structure are also presented. Finally, their photoactivity is demonstrated through photoconductivity measurements, validating their use as photodetectors and light absorbing layers for photovoltaic applications. 


\section{RESULTS AND DISCUSSION}

The synthetic method outlined herein involves the dissolution of silver and bismuth precursors in dithiocarbamic acid (DTCA) to form metal dithiocarbamate complexes. During the optimization process for the molecular precursors several different metal salts and solvent combinations were investigated. Metal acetates, metal chlorides and metal oxides as precursor salts for metal-DTC complexes, in conjunction with solvents, such as ethanol, 2methoxyethanol, DMF, DMSO, pyridine, $\gamma$-butyrolactone, and methyl ethyl ketone were all trialed. Furthermore, combinations of the aforementioned solvents were also tested to assist film formation where required. The constraints were that the final MP be stable, achievable in reasonable concentrations $(\sim 0.1 \mathrm{M})$, optically transparent (non-scattering), and have excellent film forming properties (as required to make ultra-thin films). It was found that silver acetate and bismuth oxide in pyridine was the only combination that fulfilled all these criteria. For details of the MP synthesis see the Experimental Section. The final optimized precursor the solutions can be then mixed in the desired ratio and diluted appropriately for thin film deposition.

To investigate the effect of processing (decomposition/annealing) temperature, thin films were fabricated by spin coating a metal-DTC solution with an Ag: Bi molar ratio of 1:1 and heated at different temperatures in a nitrogen-filled glove box (see Experimental section for details). Figure 1 shows the X-ray diffraction (XRD) patterns for thin films processed between $150{ }^{\circ} \mathrm{C}$ and $400{ }^{\circ} \mathrm{C}$. Analysis of the XRD confirmed highly crystalline, cubic phase $\mathrm{AgBiS}_{2}$ without any additional impurities for all the temperatures investigated. All diffraction peaks are an excellent match to the cubic schapbachite phase of $\mathrm{AgBiS}_{2}$ (space group $\mathrm{Fm} 3 \mathrm{~m}$, reference ICDD No. 21-1178). Importantly, pure phase, highly crystalline $\mathrm{AgBiS}_{2}$ was observed for decomposition (annealing) temperatures as low as $150{ }^{\circ} \mathrm{C}$. Trials at lower temperatures resulted in extremely slow decomposition and were unable to effectively produce 
high quality thin films. Close inspection of Figure 1 reveals a slight preferential orientation of $\mathrm{AgBiS}_{2}$ crystals along the $<111>$ direction. This was also observed recently for $\mathrm{AgBiS}_{2}$ films fabricated from metal nitrates and thiourea precursors. ${ }^{38}$ In light of this, the texture coefficient ${ }^{15}$ of the as-prepared $\mathrm{AgBiS}_{2}$ was calculated and the films were found the degree of orientation along the $<111>$ direction to be between $20-30 \%$. The preferential orientation was found to be fairly consistent across the investigated temperature range (see Table S1 in SI for details on the texture coefficient). In contrast, when depositing $\mathrm{AgBiS}_{2}$ by simple drop-casting of the precursor solution onto hot substrates, the orientation is lost and the diffraction peak intensity matches the tabulated values for randomly oriented materials (Figure S1). This suggests that the spin coating technique and the subsequent decomposition of the precursor as a thin film is responsible for the preferential orientation of the growing $\mathrm{AgBiS}_{2}$ crystals.

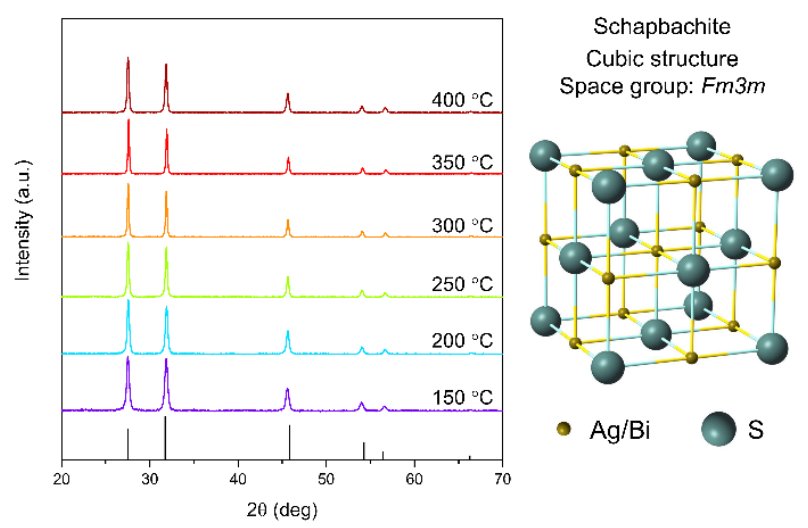

Figure 1. XRD patterns for ABS samples annealed at temperatures between $150{ }^{\circ} \mathrm{C}$ and 400 ${ }^{\circ} \mathrm{C}$. The predicted diffraction peak positions for cubic $\mathrm{AgBiS}_{2}$ (ICDD No. 21-1178), and details of the crystalline unit cell are also reported.

To estimate the average crystallite size of the prepared $\mathrm{AgBiS}_{2}$ we fitted the diffraction peaks with Lorentzian functions and extrapolated the domain size from the full width at half maximum (FWHM) through the Scherrer relationship (see Figure S2 for details). A progressive sharpening of the diffraction peaks and an increase in crystallite size from $\sim 20 \mathrm{~nm}$ at $150{ }^{\circ} \mathrm{C}$ to 
$\sim 40 \mathrm{~nm}$ at $400{ }^{\circ} \mathrm{C}$, consistent with temperature-induced grain growth (Figure S1). From scanning electron microscopy (SEM) the size of the crystalline grains as a function of temperature follow the same trend as the sizes extrapolated from the XRD patterns. Small, spheroidal $\mathrm{AgBiS}{ }_{2}$ crystals are observed at $\left(150^{\circ} \mathrm{C}\right)$, which evolve into larger, more faceted crystals with increasing annealing temperatures up to $\left(400{ }^{\circ} \mathrm{C}\right)$ (see Figure S3).

The MP method outlined herein enables facile tuning of the final compounds stoichiometry simply by changing the ratio of the silver and bismuth solutions. In order to evaluate the tolerance of the $\mathrm{AgBiS}_{2}$ crystal to deviations from the ideal stoichiometry, i.e. either bismuth-rich or silver rich, we systematically varied the volume (mole) ratios of the precursors from 2:1 (Ag:Bi) through to 1:2 (Ag:Bi). As shown in Figure 2 pure cubic $\mathrm{AgBiS}_{2}$ was obtained for compositions with up to $40 \%$ excess of either metal ( $\mathrm{Ag}: \mathrm{Bi}=1: 1.4-1.4: 1)$. From these data it is evident that the $\mathrm{AgBiS}_{2}$ structure is remarkably tolerant to variations in stoichiometry, which is likely a consequence of the fact that $\mathrm{Ag}$ and $\mathrm{Bi}$ reside at the same cation site (alternating atom type) within the cubic crystal.

The ability to change the metal ratio while keeping the desired crystalline phase is often vital to enhance the optoelectronic properties of semiconductor materials. This is especially true for ternary and quaternary chalcogenide materials. For example, stoichiometric $\mathrm{CuZnSnS}_{4}$ (CZTS) have far poorer charge transport properties and lower efficiencies as solar cells than their copper deficient and zinc rich analogues. ${ }^{19,45,46}$ Likewise, CuIn(Ga) $\mathrm{S}_{2}$ (CIGS) solar cells have optimal device performances at specific indium/gallium stoichiometry. ${ }^{47}$ The ability to tune the $\mathrm{Ag}$ : $\mathrm{Bi}$ composition of $\mathrm{AgBiS}_{2}$ thin films, as demonstrated here, is highly favorable and provides the possibility to precisely tune its semiconducting characteristics through a wide range of stoichiometric adjustments. Increasing the excess of either metal beyond $40 \%$ causes the formation of additional phases, $\mathrm{Ag}_{2} \mathrm{~S}$ (ICDD No. 14-0072) for Ag-rich compositions 
(circles), and $\mathrm{AgBi}_{3} \mathrm{~S}_{5}$ (ICDD No. 83-2051, triangles) and pure $\mathrm{Bi}_{2} \mathrm{~S}_{3}$ (ICDD No. 75-1306, stars) for Bi-rich compositions. Notably, when using either pure Bi-DTC or Ag-DTC precursor solutions, pure phase $\mathrm{Bi}_{2} \mathrm{~S}_{3}$ and $\mathrm{Ag}_{2} \mathrm{~S}$ could also be achieved (see Figure $\mathrm{S} 4$ ).

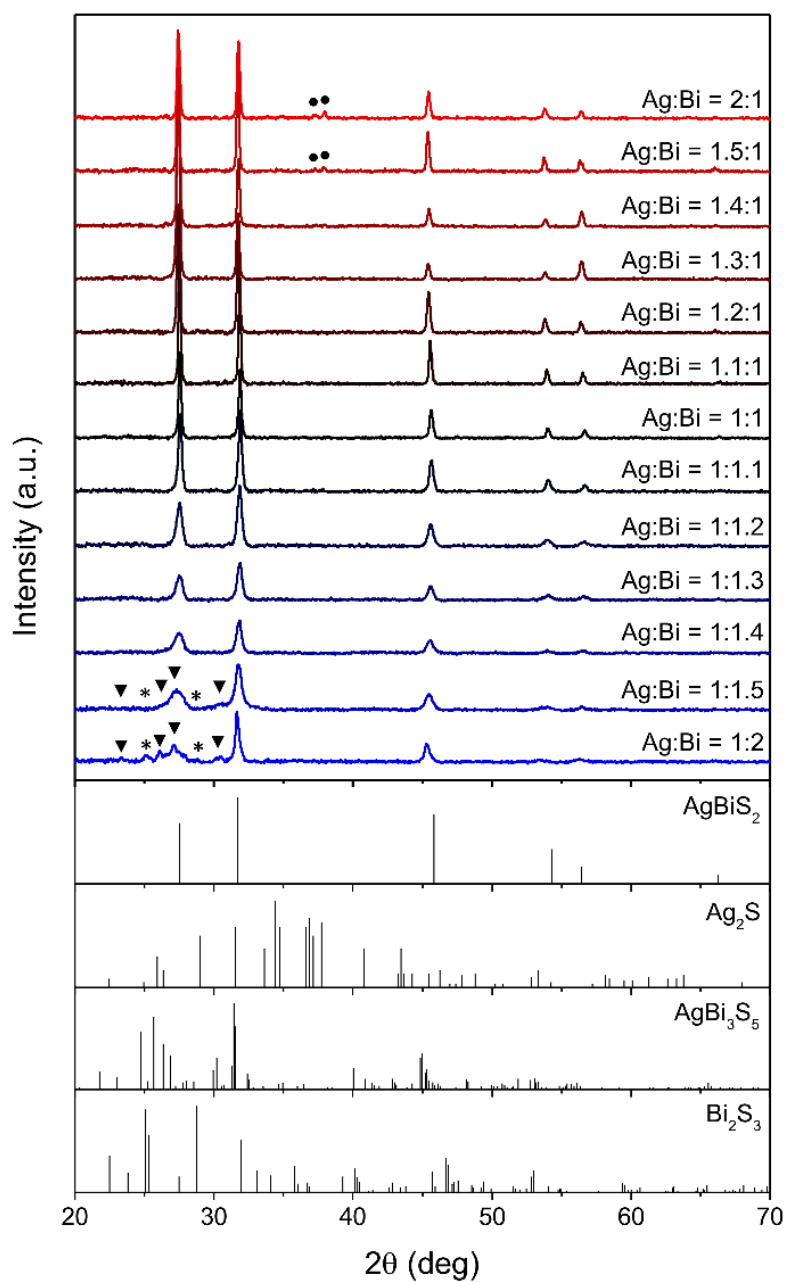

Figure 2. XRD patterns of $\mathrm{AgBiS}_{2}$ samples prepared varying the composition of the metalDTC precursors resulting in mixtures with mole ratios from $\mathrm{Ag}: \mathrm{Bi}$ 2:1 to $\mathrm{Ag}: \mathrm{Bi} \mathrm{1:2.} \mathrm{Reference}$ patterns for the target phase and impurity phases are reported at the bottom for reference. The annotations highlight the presence of impurities $\left(\mathrm{Ag}_{2} \mathrm{~S}\right.$, circles; $\mathrm{AgBi}_{2} \mathrm{~S}_{5}$, triangles and $\mathrm{Bi}_{2} \mathrm{~S}_{3}$, stars).

Having demonstrated the phase purity of our $\mathrm{AgBiS}_{2}$ films, their oxidation states and the chemical nature of the bonds within the semiconductor as a function of processing temperature were investigated using XPS. We obtained clear signatures for all the elements 
constituting $\mathrm{AgBiS}_{2}$. To rule out the effects of charging on the binding energies (BE) we measured the carbon (C 1s) signal for each sample. A clear signal peak at $284.8 \mathrm{eV}$ was obtained in each case and as such no BE corrections were required (Figure S5). Figure 3 shows the survey spectra and corresponding high-resolution spectra for the elements $\mathrm{Ag}, \mathrm{Bi}$ and $\mathrm{S}$ as a function of temperature. From the survey spectra we see the presence of the expected elements $(\mathrm{Ag}, \mathrm{Bi}, \mathrm{S})$ as well as the additional presence of trace carbon and oxygen and signal from the substrate (see Figure S5 for details). Importantly, no nitrogen was detected confirming that processing cleanly removes both solvent and any amine based decomposition products of the DTC precursors. The low oxygen signal suggests the absence of significant oxidation of our $\mathrm{AgBiS}_{2}$, even at high annealing temperatures. Analysis of the Ag 3d XPS data (Panel b) reveals binding energies of $367.8 \mathrm{eV}$ and $373.8 \mathrm{eV}$ for $\mathrm{Ag} 3 \mathrm{~d} \mathrm{5/2}$ and $\mathrm{Ag} 3 \mathrm{~d} 3 / 2$, respectively. Although the oxidation states of silver are somewhat troublesome to determine due to their small peak separation, the binding energies of the doublet match well to those previously observed for silver sulfide. ${ }^{48}$ Furthermore, the line-shape of the silver peaks are highly symmetric and indicate a single component, with no loss features are observed in the range $371-372 \mathrm{eV}$ as are typically seen in the presence of silver metal. ${ }^{49,50}$ Furthermore, the peaks have a FWHM of $\sim 1 \mathrm{eV}$ which is broader than that observed for metallic silver, and consistent with silver in an oxidized state. ${ }^{51}$ Similarly, the Bi $4 \mathrm{f}$ doublet was measured at $158.3 \mathrm{eV}$ (Bi 4f7/2) and 163.6 eV (Bi 4f5/2) (Panel c). The measured positions are intermediate between those of bismuth metal ( $\mathrm{Bi} 4 \mathrm{f} 7 / 2,157 \mathrm{eV}$ ) and bismuth oxides (Bi 4f7/2, $159 \mathrm{eV}$ ), which is expected and typical for bismuth sulfide. ${ }^{48}$ Collectively, these data are indicative of silver and bismuth as a metal sulfides $(\mathrm{Ag}(\mathrm{I}), \mathrm{Bi}(\mathrm{III}))$, as consistent with previous data on $\mathrm{AgBiS}_{2} .{ }^{37,35}$

The two low intensity peaks (within the Bi 4f region) centered at $161.2 \mathrm{eV}$ (S 2p3/2) and $162.3 \mathrm{eV}$ (S 2p1/2) correspond to the S 2p doublet (Panel c). The binding energy of the $\mathrm{S}$ $2 \mathrm{p} 3 / 2$ is consistent with a metal sulfide environment and the coupling of spin orbit components 
$(1.14 \mathrm{eV})$ and their height ratio $(0.511)$ is an excellent match to sulfur in the $2^{-}$(sulfide) state. ${ }^{52,53,54}$ In order to determine the effect of temperature on the local crystal (bonding) environment we conducted XPS of the three main elements as a function of temperature. To obtain a clearer sulfur signal, data for the $\mathrm{S} 2 \mathrm{~s}$ peak is also shown $(225.3 \mathrm{eV})$. As shown in Panels d-f for (Ag 3d), (Bi 4f) and (S 2s) respectively, no appreciable differences in either peak position or shape as a function of annealing temperatures could be observed. As such, it may be concluded that annealing temperatures in the range $\left(150{ }^{\circ} \mathrm{C}-400{ }^{\circ} \mathrm{C}\right)$, while having an effect on grain size, has little effect on the nature of the chemical bonds (local atomic environment) of the elements constituting the $\mathrm{AgBiS}_{2}$ semiconductor.
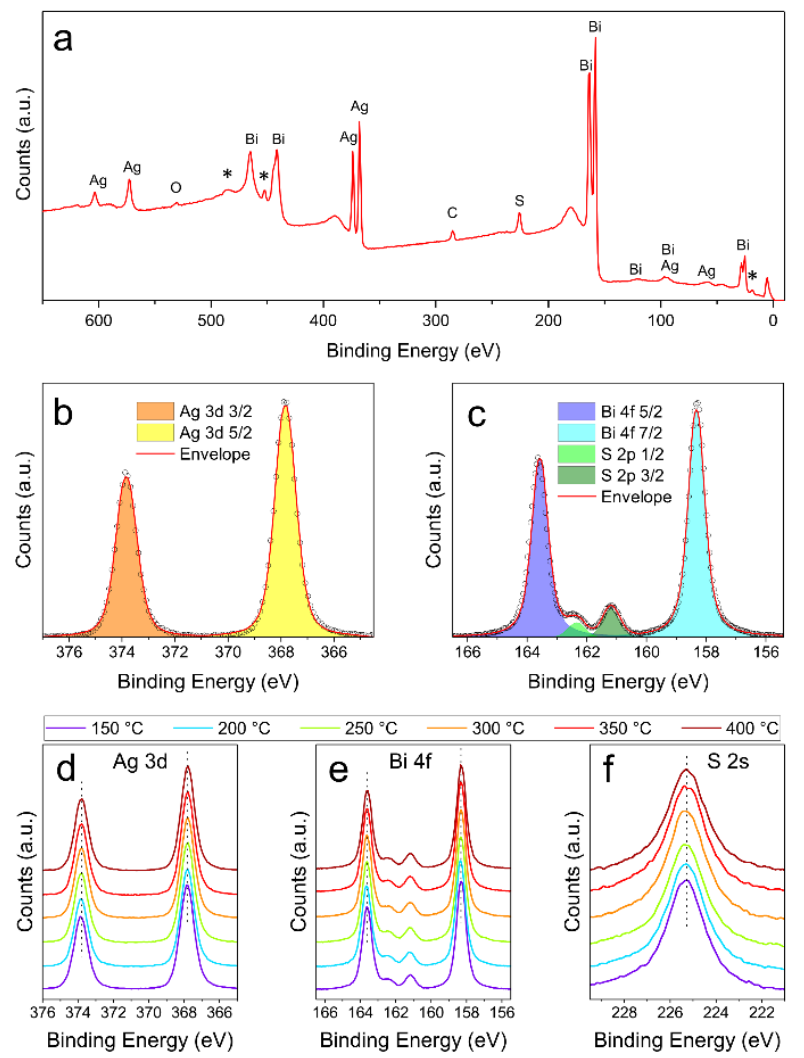

Figure 3. X-ray photoelectron spectra for stoichiometric $\mathrm{AgBiS}_{2}$ film annealed at various temperatures. a) Survey spectra of a typical sample annealed at $300{ }^{\circ} \mathrm{C}$. b) $\mathrm{Ag} 3 \mathrm{~d}$ and c) $\mathrm{Bi} 4 \mathrm{f}$ regions for a typical $\mathrm{AgBiS}_{2}$ film annealed at $300{ }^{\circ} \mathrm{C}$ showing the individual peak fittings. Panels d-f show the effects of annealing temperatures between $150-400{ }^{\circ} \mathrm{C}$ on the $\mathrm{Ag} 3 \mathrm{~d}, \mathrm{Bi}$ 4f (S 2p), and S 2s peaks respectively. 
Fabrication of high quality ultra-thin films is of paramount importance for the use of silver bismuth sulfide in efficient optoelectronic devices. In fact, it has been demonstrated that solar cells incorporating $\mathrm{AgBiS}_{2}$ as the absorber layer suffer from current losses when the absorber thickness is increased above $\sim 50 \mathrm{~nm} .{ }^{35}$ Thus, it is advantageous to be able to obtain ultra-thin dense and pinhole films within this range. By depositing multilayers from a dilute metal DTC solution ( $0.075 \mathrm{M}$ total metal concentration) we could achieve very accurate control of film thickness (down to $\sim 10 \mathrm{~nm}$ per layer). The digital photographs shown in Figure $4 \mathrm{a}$ highlight the excellent macroscopic quality of $200{ }^{\circ} \mathrm{C}$ annealed thin films with between $1-7$ layers. All $\mathrm{AgBiS}_{2}$ films show absence of scattering and strong specular reflectance properties (i.e. smooth films), and are highly absorbing, despite their low thickness in the range $\sim 30-80$ $\mathrm{nm}$.

To investigate the film morphology as a function of thickness SEM images were obtained for films with increasing layer number. Figure $4 \mathrm{~b}-\mathrm{d}$ show the SEM images of $\mathrm{AgBiS} 2$ thin films with 1, 3, and 5 layers respectively. Increasing the number of layers results in larger more defined and faceted crystal grains. Notably, dense and uniform films are observed after three layers, which have an overall thickness of $\sim 37 \mathrm{~nm}$ (Figure $4 \mathrm{c}$ ). The coating obtained after a single deposition of dilute precursor solutions is not fully continuous. This is not surprising considering the extremely thin dimension of the coating, and the large volume loss occurring when decomposing the metal-DTC precursors into metal sulfides. However, the deposition of subsequent layers fills the gaps in the $\mathrm{AgBiS}_{2}$ underlayer(s) and continuous, dense films are obtained after three layers. Figure 4e shows a plot of layer thickness as a function of the number of deposited layers. Due to incomplete coverage and densification of the thin films and variability in the wetting of the substrate thicknesses below three layers are non-linear with respect to layer number. For single layer films, the ITO substrate can be seen due to incomplete 
coverage (see arrows in Figure 4b). However, it can be clearly seen that additional depositions (>3 layers) increase the overall thickness with almost perfect linearity ( $\sim 10 \mathrm{~nm}$ per layer). As such, using the methods here dense and homogeneous ultra-thin $\mathrm{AgBiS}_{2}$ films can be fabricated with thickness as low as $37 \mathrm{~nm}$. Such ultra-thin films, as outlined here, are highly desirable and are on par with those thickness known to produce the highest efficiency $\mathrm{AgBiS}_{2}$ solar cells. ${ }^{35}$ We expect that the use of more dilute precursors $(<0.075 \mathrm{M})$ can provide high quality films with even more reduced thicknesses.

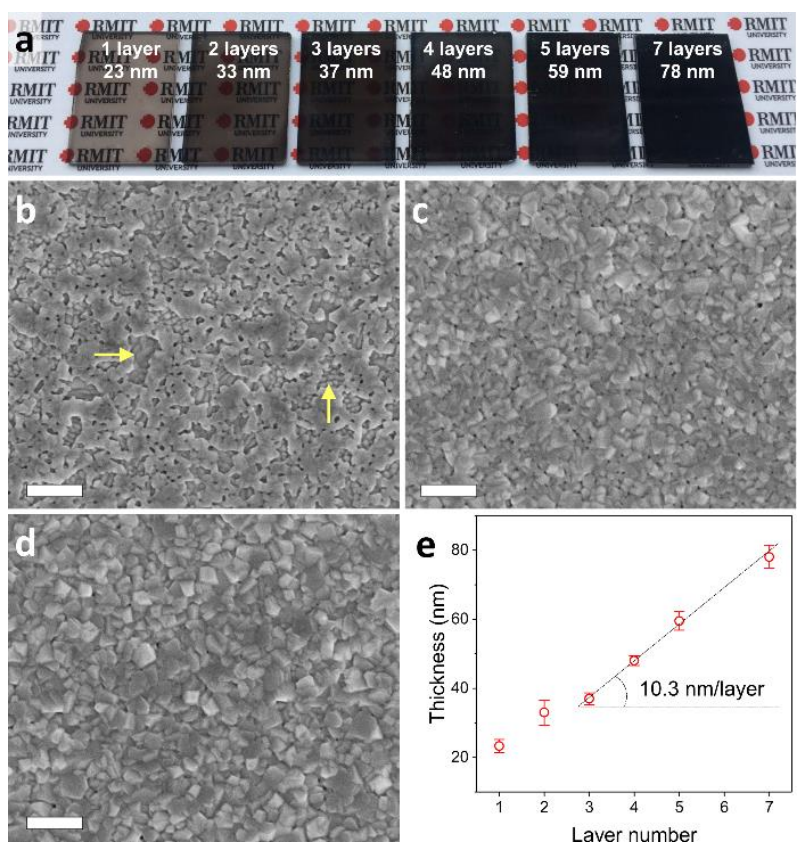

Figure 4. Top view SEM images of $\mathrm{AgBiS}_{2}$ thin films deposited from $0.075 \mathrm{M}$ precursor solutions and annealed at $300{ }^{\circ} \mathrm{C}$. a) 1 layer; b) 3 layers; c) 5 layers. The arrows in the single layer film (panel b) highlight the areas of incomplete coverage where the ITO underlayer is visible. All scale bars are $200 \mathrm{~nm}$. d) Plot of thickness as a function of the number of deposited layers, showing a typical value of $\sim 10 \mathrm{~nm}$ per layer.

Given the ultra-thin nature of the films and the rigorous requirements for (opto)electronic device incorporation, the quality of thin films is best assessed by viewing the films in cross sectional SEM. Figure 5 shows SEM images in cross-section for $\mathrm{AgBiS}_{2}$ films (5 layers, 55-60 nm) on Glass/ITO substrates annealed at $150^{\circ} \mathrm{C}, 200^{\circ} \mathrm{C}$, and $300^{\circ} \mathrm{C}$. Dense, smooth and crystalline $\mathrm{AgBiS}_{2}$ films can be seen for all temperatures, with a slight increase in 
surface roughness at higher annealing temperatures, consistent with the larger crystal grain sizes obtained when annealing at $300{ }^{\circ} \mathrm{C}$ compared to lower temperatures. The corresponding top view SEM images are shown alongside each temperature. At $150{ }^{\circ} \mathrm{C}$ the film is seen to be highly uniform although the $\mathrm{AgBiS}_{2}$ crystal grains are less faceted compared to those observed at $200{ }^{\circ} \mathrm{C}$. Annealing at $300{ }^{\circ} \mathrm{C}$ causes the grains to become more faceted with well-defined grain boundaries. The data from Figure 5 (in conjunction with the previous XRD data) confirms that using the optimized methods outlined here dense highly crystalline thin films of $\mathrm{AgBiS}_{2}$ can be obtained at processing temperatures as low as $150{ }^{\circ} \mathrm{C}$. We attribute the ability to form high quality films at such low temperatures to the use of metal-DTC precursors, which are known to decompose at reduced temperatures compared to analogous metal thiourea complexes. ${ }^{55,56}$

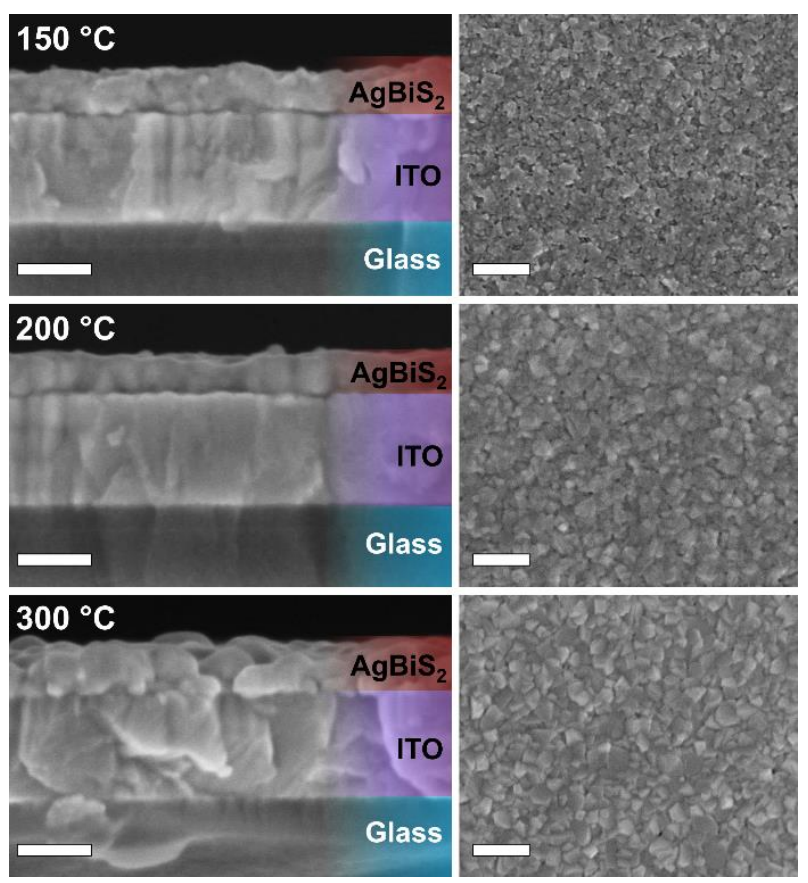

Figure 5. Cross sectional (left panels) and top view (right panels) SEM images of $\mathrm{AgBiS}_{2}$ films deposited on ITO and annealed at $150{ }^{\circ} \mathrm{C}, 200^{\circ} \mathrm{C}$ and $300^{\circ} \mathrm{C}$. Scale bars are $100 \mathrm{~nm}$ for cross sections and $200 \mathrm{~nm}$ for top views. Each sample has been fabricated depositing 5 layers ( $\sim 55$ $\mathrm{nm}$ ) of a $0.075 \mathrm{M}$ DTC solution, annealing each layer directly at the desired temperature. 
Having optimized the formation of dense thin films, the optical properties of the asprepared $\mathrm{AgBiS}_{2}$ films could then be confidently investigated. Figure 6 shows the results of a comprehensive study into optical properties of the films prepared at different annealing temperatures. The $\mathrm{AgBiS}_{2}$ films were found to have an absorption onset at around $1200 \mathrm{~nm}$ (Figure S6). Figure 6a shows the results of extrapolating the optical band gap using Tauc analysis. A direct band gap value of $\sim 1.1 \mathrm{eV}$ is observed for all temperatures between 200-300 ${ }^{\circ} \mathrm{C}$. The measured band gap was slightly larger for the lower annealing temperature of $150{ }^{\circ} \mathrm{C}$ $(\sim 1.15 \mathrm{eV})$. Further increases to the annealing temperatures resulted reductions to the band gap of less than $50 \mathrm{meV}$, with values of $1.06 \mathrm{eV}\left(350{ }^{\circ} \mathrm{C}\right)$ and $1.05 \mathrm{eV}\left(400{ }^{\circ} \mathrm{C}\right)$. From further analysis of the films we viewed an indirect component at $\sim 0.9 \mathrm{eV}$ (Figure S7), similar to recently reported data. ${ }^{38}$ The dense, smooth and uniform nature of the thin films (with a precise thickness) enables accurate evaluation of the absorption coefficient, which is presented in Figure $6 \mathrm{~b}$. Remarkable values of alpha $>10^{5} \mathrm{~cm}^{-1}$ are achieved in the visible-NIR wavelength range (above $960 \mathrm{~nm}$ ), putting $\mathrm{AgBiS}_{2}$ on par with the best known semiconductor light absorbers $\left(\mathrm{CdTe}^{57}, \mathrm{CH}_{3} \mathrm{NH}_{3} \mathrm{PbI}_{3}{ }^{58}, \mathrm{GaAs}^{59}\right.$ etc). Compared to recent works on $\mathrm{AgBiS}_{2}$ thin films we achieved a slightly larger absorption coefficient. ${ }^{35,38} \mathrm{We}$ ascribe this to the high density of the films prepared here, which are unlike previously reported $\mathrm{AgBiS}_{2}$ films, especially those fabricated from colloidal nanocrystals, which incorporate a large fraction of pores.

We also evaluated the band structure of $\mathrm{AgBiS}_{2}$ combining photoelectron spectroscopy in air (PESA) and valence-band XPS. PESA enables to measure the ionization potential of thin films, which corresponds to the valence band edge in a semiconductor (or the HOMO level in an organic material). This technique has been widely adopted to estimate valence band positions in various semiconducting materials including oxides and chalcogenides. ${ }^{60,}{ }^{22},{ }^{61}$ 
Analysis of the valence band (VB) region using XPS enables estimation of the energy difference between the Fermi level and the valence band edge. Figure $6 \mathrm{c}$ shows typical PESA and VB-XPS (inset) data collected for films annealed at $300{ }^{\circ} \mathrm{C}$. The dotted lines show the linear fits used to determine the VB edge and the Fermi level offset. The spectra were then collected for a range of annealing temperatures. The PESA and valence band XPS spectra for $\mathrm{AgBiS}_{2}$ samples annealed at different temperatures can be viewed in Figures S8 and S9. Using these data, in conjunction with the band gap energy (from Tauc analysis), simplified band structures can be drawn. From the band structures presented in Figure $6 \mathrm{~d}$ we can conclude that $\mathrm{AgBiS}_{2}$ is an almost intrinsic (slightly n-type) semiconductor, as the Fermi energy lies roughly in the middle of the band gap. Interestingly, we note that the films produced using DTC precursors are naturally more intrinsic than those of as-prepared $\mathrm{AgBiS}_{2}$ nanocrystals, which are n-type and require ligand stripping and iodine doping to yield an intrinsic semiconductor. ${ }^{35}$ Overall, annealing temperature was observed to have little effect on the band structure within the temperature range investigated here (see Figure 6d and Table S2 in Supporting information for details). In addition, phase-pure $\mathrm{AgBiS}_{2}$ films with off-stoichiometric compositions - up to $40 \%$ excess of either metal $(\mathrm{Ag}: \mathrm{Bi}=1: 1.4-1.4: 1)$, see Figure $2-$ showed small variations in band gap energy, without a clear trend with composition as presented in Figure S10. However, a weak trend in valence band energy could be identified using PESA, with the bismuth-rich samples having a slightly deeper valence band than the silver-rich samples (Figure S11). It is worth noting that the maximum variation both in band gap and valence band energies is within $\sim 0.1 \mathrm{eV}$, therefore the effect is rather small. 

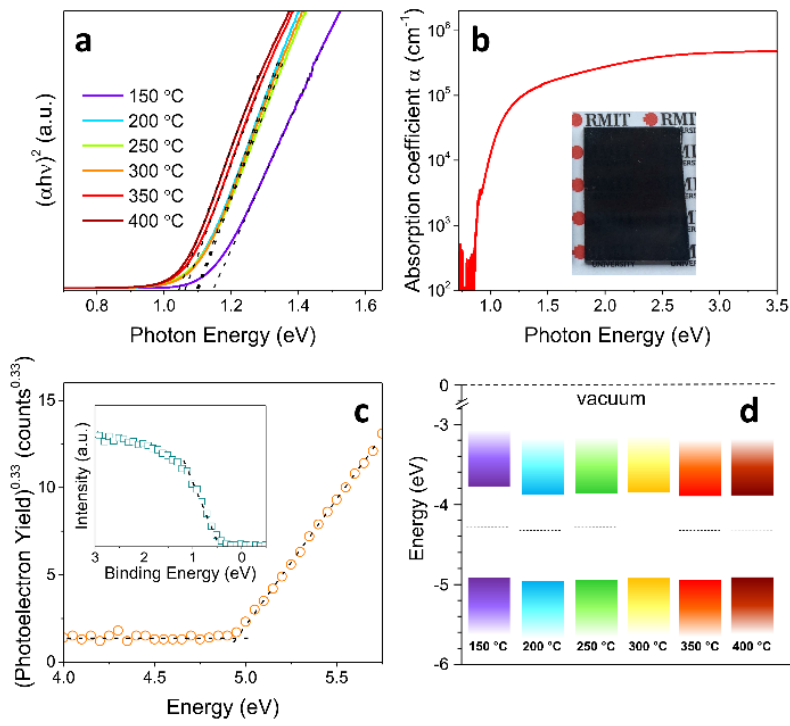

Figure 6. a) dTauc plot assuming direct allowed transition for typical $\mathrm{AgBiS}_{2}$ films annealed at different temperatures, showing a band gap value of about $1.1 \mathrm{eV} . \mathrm{b}$ ) Absorption coefficient for a typical $\mathrm{AgBiS}_{2}$ sample annealed at $300{ }^{\circ} \mathrm{C}$ as a function of radiation energy. The inset shows a digital photograph of a $60 \mathrm{~nm}$ thick film. c) Photoelectron yield as a function of energy of the incident radiation as measured with PESA for a typical $\mathrm{AgBiS}_{2}$ sample annealed at 300 ${ }^{\circ} \mathrm{C}$. The inset shows the valence band XPS spectrum for the same sample. d) Schematic band diagram for $\mathrm{AgBiS}_{2}$ films as a function of annealing temperature.

In order to assess the potential performance of our $\mathrm{AgBiS}_{2}$ films as light absorbers in photovoltaic devices, we conducted preliminary tests of their ability to generate photocurrent. $\mathrm{AgBiS}_{2}$ films were deposited on lithographically patterned Au electrodes and exposed to pulsed green $(530 \mathrm{~nm})$ light using a commercial light emitting diode (LED). A fast and reversible photocurrent was observed in all samples tested, indicating the potential of the films for photovoltaic device integration. The tests were performed under inert gas environment which was observed to provide a more stable and reproducible baseline signal (dark current) compared to measurements performed in ambient air. Notably, the sample processed at $200{ }^{\circ} \mathrm{C}$ showed a drastic improvement in the on/off ratio $(\sim 2.2)$ compared to samples annealed at either higher $\left(300^{\circ} \mathrm{C}\right)$ or lower $\left(150^{\circ} \mathrm{C}\right)$ temperatures. The observed on/off ratios are similar to those 
observed previously for photo-conductivity measurements employing lateral electrodes. ${ }^{38,62}$ From the data of Figure 7 it is clear that the photocurrent generation from $\mathrm{AgBiS}_{2}$ thin films is extremely sensitive to the processing temperature used. The narrow temperature window to achieve optimal performance observed here is consistent with previous work on $\mathrm{AgBiS}_{2}$, which showed drastic differences in both the optical properties and solar cell device performance (short circuit current) with very small changes to the processing temperature between 125-225 ${ }^{\circ} \mathrm{C} .{ }^{37}$ In fact, optimization of processing temperature to achieve maximum (thin film) device currents is commonly observed for semiconductors. ${ }^{63,64}$ Typically, higher processing temperatures result in improved grain growth and crystallinity and subsequent improvements to photocurrent. As such, the reduced photocurrent at $300{ }^{\circ} \mathrm{C}$, although somewhat unexpected again highlights the critical importance on processing temperatures for this system. Elucidating the nature of the seemingly narrow processing temperature window for $\mathrm{AgBiS}_{2}$ proves to be an interesting topic for further, more rigorous investigation. Finally, the high quality of our $\mathrm{AgBiS}_{2}$ films is also evidenced through extended testing under chopped light (Figure S12), which shows excellent reproducibility and stability of both the dark current and photocurrent values. 


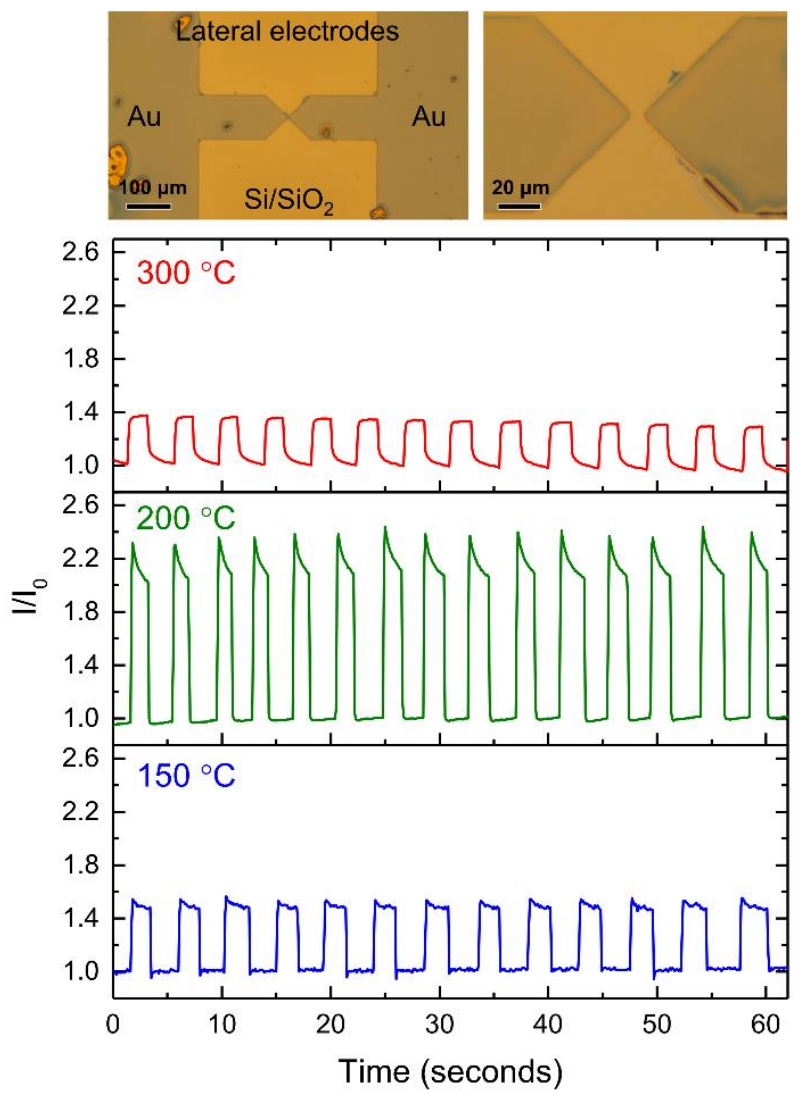

Figure 7. Top panels: optical microscope images of the $\mathrm{AgBiS}_{2}$ film deposited on pre-patterned $\mathrm{Au}$ electrodes. Bottom panel: Photoconductivity as a function of time for $\mathrm{AgBiS}_{2}$ annealed at different temperatures under pulsed green (530 nm LED) light illumination.

\section{CONCLUSION}

Through careful optimization of the precursors and solvents we have developed a stable molecular precursor capable of fabricating pure phase ultra-thin $(<40 \mathrm{~nm})$ device quality $\mathrm{AgBiS}_{2}$ films. Through mixing the precursor solution in the desired ratios, dense films of tunable composition with up to $40 \%$ excess of either metal can be achieved without the segregation of impurity phases. Detailed spectroscopic (optical, XPS, PESA) and structural (XRD, SEM) analyses confirm that highly crystalline $\mathrm{AgBiS}_{2}$ films can be achieved at temperatures as low as $150{ }^{\circ} \mathrm{C}$ and up to $400{ }^{\circ} \mathrm{C}$ without compromising film quality or the materials electronic structure and phase purity. An optical band gap of $\sim 1.1 \mathrm{eV}$ and a striking 
absorption coefficient $>10^{5} \mathrm{~cm}^{-1}$ in the visible range have been measured for our optimized

films. Preliminary photocurrent measurements using lithographically patterned lateral electrodes under chopped visible $(530 \mathrm{~nm})$ light show a fast and reversible photo-response. Collectively, the low temperature processing conditions, high film quality, and the tunability of $\mathrm{Ag} / \mathrm{Bi}$ composition make the $\mathrm{AgBiS}_{2}$ thin films developed here highly desirable for optoelectronic applications and ideal for photovoltaic device integration.

\section{EXPERIMENTAL}

\section{Materials}

Silver acetate (99.99\%), n-butylamine (99.5\%), carbon disulfide $\left(\mathrm{CS}_{2},>99.9 \%\right)$, pyridine (> 99.9\%) were supplied by Sigma-Aldrich. Bismuth oxide (99.999\%) was supplied by Strem Chemicals. All chemicals were used without further purification.

\section{Precursor synthesis}

All procedures reported below have been conducted in a fume hood. n-butyl dithiocarbamic acid (DTCA) was prepared by first reacting $n$-butylamine with $\mathrm{CS}_{2}$. Specifically, $7.2 \mathrm{mmol}(0.526 \mathrm{~g}) n$-butylamine was mixed with $1.831 \mathrm{~mL}$ pyridine in a glass vial and let stir in an ice bath for $15 \mathrm{~min}$. Then $7.56 \mathrm{mmol} \mathrm{CS}_{2}(0.576 \mathrm{~g}$, a 5\% excess compared to the stoichiometric 1:1 amount with $n$-butylamine) was added dropwise under strong stirring. A color change from colorless to deep yellow was observed during the addition of $\mathrm{CS}_{2}$. The solutions are let stir for an additional 5 minutes in the ice bath, and then are removed from the bath and let warm up naturally to room temperature under constant stirring.

This DTCA solution was used to dissolve either $0.6 \mathrm{mmol}$ silver acetate $(0.1001 \mathrm{~g})$ or 0.3 mmol bismuth oxide $(0.1398 \mathrm{~g})$, in order to keep a 1:12 molar ratio between the metal and the DTCA (every bismuth oxide molecule contributes with two bismuth atoms), and a metal 
concentration of $0.2 \mathrm{M}$ for both $\mathrm{Ag}$ and $\mathrm{Bi}$ solutions. In the case of silver, some black precipitates form immediately after mixing, but they re-dissolve within $1 \mathrm{hr}$, forming a stable dark yellow solution of Ag-DTC complex. ${ }^{65}$ Bismuth oxide requires a few days of constant stirring to fully dissolve into a deep red Bi-DTC complex. These equimolar solutions could then be mixed in 1:1 volume ratio to achieve stoichiometric $\mathrm{AgBiS}_{2}$ precursors or mixed in the desired ratio for non-stoichiometric formulations. Notably, these molecular precursors are stable for several months if stored in an inert (oxygen and water free) environment. Moreover, these solutions could be further diluted with pyridine for the deposition of ultra-thin layers. Given pyridine contains an amine, pure pyridine solutions (without $n$-butlyamine) were tested to evaluate the possible speciation of the precursor with the solvent. We note here that in the absence of $n$-butylamine no dissolution of the metal salts was observed, indicating that pyridine is unable to form a DTC complex with $\mathrm{CS}_{2}$. This is expected given the greatly reduced reactivity (nucleophilicity) of secondary amines compared to primary amines.

\section{Thin-film deposition}

Thin films were deposited by spin coating on various substrates (glass, Si, glass/ITO or pre-patterned $\mathrm{Si} / \mathrm{SiO}_{2} / \mathrm{Au}$ samples, see below) which were pre-cleaned through washing in acetone and isopropanol. All depositions and annealing have been conducted in a nitrogenfilled glove box $\left(\mathrm{H}_{2} \mathrm{O} / \mathrm{O}_{2}\right.$ concentration $\left.<10 \mathrm{ppm}\right)$. Thick films for XRD analysis were prepared by spin coating 2 layers of a $0.2 \mathrm{M}$ solution of metal precursors in the desired ratio at $3000 \mathrm{rpm}$ for 30 seconds and annealed directly at the desired temperature on a preheated hotplate for 10 minutes. Drop-cast samples were prepared by preheating the substrate on a hotplate at the desired temperature, and by dropping the precursors solution slowly, giving time for the deposited material to decompose between additions. 
Thin multilayered samples were prepared from $0.075 \mathrm{M}$ precursor solutions, using 5000 rpm as the spin speed and annealing directly at the desired temperature for 2 minutes each layer. For samples annealed at $150{ }^{\circ} \mathrm{C}$ and $200{ }^{\circ} \mathrm{C}$, longer baking times (10 and 5 minutes respectively) are needed for each layer to fully stabilize in order to avoid material delamination when depositing subsequent layers. All samples made in this study are stoichiometric (Ag:Bi $=1: 1)$ unless specified otherwise.

\section{Characterization techniques}

X-ray diffraction (XRD) patterns of thin films were collected using a Bruker D4 Endeavor diffractometer equipped with a $\mathrm{Cu}-\mathrm{K} \alpha$ radiation source and operated at $40 \mathrm{kV}$ and $35 \mathrm{~mA}$. The crystallite size was evaluated with the Scherrer relationship using the full width at half-maximum of the diffraction peaks fitted using Lorentzian functions. For each sample the extracted size values from each of the diffraction peaks were averaged and the error was calculated as one standard deviation. X-ray Photoelectron Spectroscopy (XPS) was conducted on a Thermo Scientific K-Alpha XPS equipped with a Monochromated Al Ka X-ray source $\left(\mathrm{E}_{\text {photon }}=1486.7 \mathrm{eV}\right), \mathrm{X}$-ray spot size: $30-400 \mu \mathrm{m}$ in $5 \mu \mathrm{m}$ steps. Scanning electron microscopy (SEM) images were acquired on a FEI Verios 460L SEM operated at $2 \mathrm{kV}$ and 25 pA. Thickness values were acquired with a KLA Tencor P-16+ Surface Profiler and validated with cross-sectional SEM images. Optical transmission (T) and reflection (R) spectra of $\mathrm{AgBiS}_{2}$ films were acquired with a Cary $7000 \mathrm{UV}-\mathrm{Vis}-\mathrm{NIR}$ spectrometer equipped with an integrating sphere. The absorption coefficient $\alpha$ was calculated from transmission and reflection data using the following formula:

$$
\alpha=\frac{1}{d} \ln \left(\frac{1-R}{T}\right)
$$

where $d$ is the $\mathrm{AgBiS}_{2}$ thickness. Photoelectron spectroscopy in air (PESA) measurements were conducted on a Riken-Keiki spectrophotometer using an incident radiation power of $5 \mathrm{nW}$. The 
electrical measurements as a function of light illumination were conducted on $\mathrm{AgBiS}_{2}$ thin films deposited onto pre-patterned Au electrodes under a constant flow of nitrogen. The current under light and dark conditions was measured using a Keysight 2900 sourcemeter applying a constant voltage of $0.5 \mathrm{~V}$. A green $(530 \mathrm{~nm})$ light-emitting diode (LED, Thorlabs, Inc.) was utilized as light source. The illumination power was calibrated using a silicon photodetector (Newport Corporation) and kept constant at $12 \mathrm{~mW} / \mathrm{cm}^{2}$.

\section{AUTHOR INFORMATION}

\section{Corresponding Author}

*Email: joel.vanembden@rmit.edu.au (JvE); enrico.dellagaspera@rmit.edu.au (EDG)

\section{Author Contributions}

The manuscript was written through contributions of all authors. All authors have given approval to the final version of the manuscript.

\section{ACKNOWLEDGMENT}

The Australian Research Council is acknowledged for supporting this work through two Discovery Early Career Researcher Awards (DE150100427, JvE ; DE170100164, EDG). EDG thanks RMIT University for a Vice Chancellor Fellowship. The authors acknowledge the facilities and the technical assistance of the RMIT University’s Microscopy and Microanalysis Facility (RMMF) and MicroNano Research Facility (MNRF). The authors would also like to thank Dr Taimur Ahmed for facilitating the photoconductivity measurements, and Dr. Anthony Chesman and Dr Thomas Gengenbach at the CSIRO for assistance with PESA and XPS measurements.

\section{REFERENCES}


1. Aksay, I. A.; Trau, M.; Manne, S.; Honma, I.; Yao, N.; Zhou, L.; Fenter, P.; Eisenberger, P. M.; Gruner, S. M., Biomimetic Pathways for Assembling Inorganic Thin Films. Science 1996, 273 (5277), 892-898.

2. Lange, F. F., Chemical Solution Routes to Single-Crystal Thin Films. Science 1996, 273 (5277), 903-909.

3. Caruso, R. A.; Antonietti, M., Sol-Gel Nanocoating: An Approach to the Preparation of Structured Materials. Chemistry of Materials 2001, 13 (10), 3272-3282.

4. Sun, B.; Sirringhaus, H., Solution-Processed Zinc Oxide Field-Effect Transistors Based on Self-Assembly of Colloidal Nanorods. Nano Letters 2005, 5 (12), 2408-2413.

5. Todorov, T. K.; Reuter, K. B.; Mitzi, D. B., High-Efficiency Solar Cell with EarthAbundant Liquid-Processed Absorber. Advanced Materials 2010, 22 (20), E156-E159.

6. Sun, Y.; Gates, B.; Mayers, B.; Xia, Y., Crystalline Silver Nanowires by Soft Solution Processing. Nano Letters 2002, 2 (2), 165-168.

7. Kim, H.-S.; Cook, J. B.; Lin, H.; Ko, Jesse S.; Tolbert, Sarah H.; Ozolins, V.; Dunn, B., Oxygen vacancies enhance pseudocapacitive charge storage properties of $\mathrm{MoO} 3-\mathrm{x}$. Nature Materials 2016, 16, 454.

8. McDonald, S. A.; Konstantatos, G.; Zhang, S.; Cyr, P. W.; Klem, E. J. D.; Levina, L.; Sargent, E. H., Solution-processed $\mathrm{PbS}$ quantum dot infrared photodetectors and photovoltaics. Nature Materials 2005, 4, 138.

9. Sanchez, C.; Julián, B.; Belleville, P.; Popall, M., Applications of hybrid organicinorganic nanocomposites. Journal of Materials Chemistry 2005, 15 (35-36), 3559-3592.

10. Gaspera, E.; Martucci, A., Sol-Gel Thin Films for Plasmonic Gas Sensors. Sensors 2015, 15 (7), 16910.

11. Cargnello, M.; Jaén, J. J. D.; Garrido, J. C. H.; Bakhmutsky, K.; Montini, T.; Gámez, J. J. C.; Gorte, R. J.; Fornasiero, P., Exceptional Activity for Methane Combustion over Modular Pd@CeO $<$ sub $>2</$ sub $>$ Subunits on Functionalized $\mathrm{Al}<\mathrm{sub}>2</$ sub $>\mathrm{O}<\mathrm{sub}>3</$ sub $>$. Science 2012, 337 (6095), 713-717.

12. Paglia, F.; Vak, D.; van Embden, J.; Chesman, A. S. R.; Martucci, A.; Jasieniak, J. J.; Della Gaspera, E., Photonic Sintering of Copper through the Controlled Reduction of Printed $\mathrm{CuO}$ Nanocrystals. ACS Applied Materials \& Interfaces 2015, 7 (45), 25473-25478.

13. Jasieniak, J. J.; Treat, N. D.; McNeill, C. R.; de Villers, B. J. T.; Della Gaspera, E.; Chabinyc, M. L., Interfacial Characteristics of Efficient Bulk Heterojunction Solar Cells Fabricated on MoOx Anode Interlayers. Advanced Materials 2016, 28 (20), 3944-3951.

14. Nair, P. K.; Nair, M. T. S.; García, V. M.; Arenas, O. L.; Peña, A. C. Y.; Ayala, I. T.; Gomezdaza, O.; Sánchez, A.; Campos, J.; Hu, H.; Suárez, R.; Rincón, M. E., Semiconductor thin films by chemical bath deposition for solar energy related applications. Solar Energy Materials and Solar Cells 1998, 52 (3), 313-344.

15. Della Gaspera, E.; van Embden, J.; Chesman, A. S. R.; Duffy, N. W.; Jasieniak, J. J., Mimicry of Sputtered i-ZnO Thin Films Using Chemical Bath Deposition for SolutionProcessed Solar Cells. ACS Applied Materials \& Interfaces 2014, 6 (24), 22519-22526.

16. Della Gaspera, E.; Kennedy, D. F.; van Embden, J.; Chesman, A. S. R.; Gengenbach, T. R.; Weber, K.; Jasieniak, J. J., Flash-Assisted Processing of Highly Conductive Zinc Oxide Electrodes from Water. Advanced Functional Materials 2015, 25 (47), 7263-7271.

17. Tsin, F.; Venerosy, A.; Vidal, J.; Collin, S.; Clatot, J.; Lombez, L.; Paire, M.; Borensztajn, S.; Broussillou, C.; Grand, P. P.; Jaime, S.; Lincot, D.; Rousset, J., Electrodeposition of $\mathrm{ZnO}$ window layer for an all-atmospheric fabrication process of chalcogenide solar cell. Scientific Reports 2015, 5, 8961.

18. Chang, J. A.; Rhee, J. H.; Im, S. H.; Lee, Y. H.; Kim, H.-j.; Seok, S. I.; Nazeeruddin, M. K.; Gratzel, M., High-Performance Nanostructured Inorganic-Organic Heterojunction Solar Cells. Nano Letters 2010, 10 (7), 2609-2612. 
19. van Embden, J.; Chesman, A. S. R.; Della Gaspera, E.; Duffy, N. W.; Watkins, S. E.; Jasieniak, J. J., Cu2ZnSnS4xSe4(1-x) Solar Cells from Polar Nanocrystal Inks. Journal of the American Chemical Society 2014, 136 (14), 5237-5240.

20. Choi, J.-H.; Wang, H.; Oh, S. J.; Paik, T.; Sung, P.; Sung, J.; Ye, X.; Zhao, T.; Diroll, B. T.; Murray, C. B.; Kagan, C. R., Exploiting the colloidal nanocrystal library to construct electronic devices. Science 2016, 352 (6282), 205-208.

21. Morfa, A. J.; Beane, G.; Mashford, B.; Singh, B.; Della Gaspera, E.; Martucci, A.; Mulvaney, P., Fabrication of $\mathrm{ZnO}$ Thin Films from Nanocrystal Inks. The Journal of Physical Chemistry C 2010, 114 (46), 19815-19821.

22. Chesman, A. S. R.; van Embden, J.; Della Gaspera, E.; Duffy, N. W.; Webster, N. A. S.; Jasieniak, J. J., Cu2ZnGeS4 Nanocrystals from Air-Stable Precursors for Sintered Thin Film Alloys. Chemistry of Materials 2014, 26 (19), 5482-5491.

23. Talapin, D. V.; Lee, J.-S.; Kovalenko, M. V.; Shevchenko, E. V., Prospects of Colloidal Nanocrystals for Electronic and Optoelectronic Applications. Chemical Reviews 2010, 110 (1), 389-458.

24. Brinker, C. J.; Scherer, G. W., Sol-Gel Science: The Physics and Chemistry of Sol-Gel Processing. Academic Press: San Diego, CA, 1990.

25. Ki, W.; Hillhouse, H. W., Earth-Abundant Element Photovoltaics Directly from Soluble Precursors with High Yield Using a Non-Toxic Solvent. Advanced Energy Materials 2011, 1 (5), 732-735.

26. Della Gaspera, E.; Buso, D.; Guglielmi, M.; Martucci, A.; Bello, V.; Mattei, G.; Post, M. L.; Cantalini, C.; Agnoli, S.; Granozzi, G.; Sadek, A. Z.; Kalantar-zadeh, K.; Wlodarski, W., Comparison study of conductometric, optical and SAW gas sensors based on porous solgel silica films doped with $\mathrm{NiO}$ and Au nanocrystals. Sensors and Actuators B: Chemical 2010, 143 (2), 567-573.

27. Kim, J. W.; Augustyn, V.; Dunn, B., The Effect of Crystallinity on the Rapid Pseudocapacitive Response of Nb2O5. Advanced Energy Materials 2012, 2 (1), 141-148.

28. Tseng, I. H.; Chang, W.-C.; Wu, J. C. S., Photoreduction of CO2 using sol-gel derived titania and titania-supported copper catalysts. Applied Catalysis B: Environmental 2002, 37 (1), 37-48.

29. Uhl, A. R.; Katahara, J. K.; Hillhouse, H. W., Molecular-ink route to $13.0 \%$ efficient low-bandgap CuIn(S,Se)2 and $14.7 \%$ efficient $\mathrm{Cu}(\mathrm{In}, \mathrm{Ga})(\mathrm{S}, \mathrm{Se}) 2$ solar cells. Energy \& Environmental Science 2016, 9 (1), 130-134.

30. McCarthy, C. L.; Brutchey, R. L., Solution processing of chalcogenide materials using thiol-amine "alkahest" solvent systems. Chemical Communications 2017, 53 (36), 4888-4902.

31. Xia, Z.; Zhong, J.; Leng, M.; Hu, L.; Xue, D.-J.; Yang, B.; Zhou, Y.; Liu, X.; Qin, S.; Cheng, Y.-B.; Tang, J., Generalized Water-Processed Metal Chalcogenide Complexes: Synthesis and Applications. Chemistry of Materials 2015, 27 (23), 8048-8057.

32. Tian, Q.; Wang, G.; Zhao, W.; Chen, Y.; Yang, Y.; Huang, L.; Pan, D., Versatile and Low-Toxic Solution Approach to Binary, Ternary, and Quaternary Metal Sulfide Thin Films and Its Application in $\mathrm{Cu} 2 \mathrm{ZnSn}(\mathrm{S}, \mathrm{Se}) 4$ Solar Cells. Chemistry of Materials 2014, 26 (10), 3098-3103.

33. van Embden, J.; Chesman, A. S. R.; Jasieniak, J. J., The Heat-Up Synthesis of Colloidal Nanocrystals. Chemistry of Materials 2015, 27 (7), 2246-2285.

34. Huang, P.-C.; Yang, W.-C.; Lee, M.-W., AgBiS2 Semiconductor-Sensitized Solar Cells. The Journal of Physical Chemistry C 2013, 117 (36), 18308-18314.

35. Bernechea, M.; Miller, N. C.; Xercavins, G.; So, D.; Stavrinadis, A.; Konstantatos, G., Solution-processed solar cells based on environmentally friendly AgBiS2 nanocrystals.

Nature Photonics 2016, 10, 521. 
36. Hu, L.; Patterson, R. J.; Zhang, Z.; Hu, Y.; Li, D.; Chen, Z.; Yuan, L.; Teh, Z. L.; Gao, Y.; Conibeer, G. J.; Huang, S., Enhanced optoelectronic performance in AgBiS2 nanocrystals obtained via an improved amine-based synthesis route. Journal of Materials Chemistry C 2018, 6 (4), 731-737.

37. Pai, N.; Lu, J.; Senevirathna, D. C.; Chesman, A. S. R.; Gengenbach, T.; Chatti, M.; Bach, U.; Andrews, P. C.; Spiccia, L.; Cheng, Y.-B.; Simonov, A. N., Spray deposition of $\mathrm{AgBiS} 2$ and Cu3BiS3 thin films for photovoltaic applications. Journal of Materials Chemistry C 2018, 6 (10), 2483-2494.

38. Gu, E.; Lin, X.; Tang, X.; Matt, G. J.; Osvet, A.; Hou, Y.; Jäger, S.; Xie, C.; Karl, A.; Hock, R.; Brabec, C. J., Single molecular precursor ink for AgBiS2 thin films: synthesis and characterization. Journal of Materials Chemistry C 2018, 6 (28), 7642-7651.

39. Pejova, B.; Grozdanov, I.; Nesheva, D.; Petrova, A., Size-Dependent Properties of Sonochemically Synthesized Three-Dimensional Arrays of Close-Packed Semiconducting AgBiS2 Quantum Dots. Chemistry of Materials 2008, 20 (7), 2551-2565.

40. Nakamura, M.; Nakamura, H.; Ohsawa, T.; Imura, M.; Shimamura, K.; Ohashi, N., AgBiS2 single crystal grown using slow cooling method and its characterization. Journal of Crystal Growth 2015, 411, 1-3.

41. Thongtem, T.; Tipcompor, N.; Thongtem, S., Characterization of AgBiS2 nanostructured flowers produced by solvothermal reaction. Materials Letters 2010, 64 (6), $755-758$.

42. Chen, D.; Shen, G.; Tang, K.; Jiang, X.; Huang, L.; Jin, Y.; Qian, Y., Microwave synthesis of $\mathrm{AgBiS} 2$ dendrites in aqueous solution. Inorganic Chemistry Communications 2003, 6 (6), 710-712.

43. Pejova, B.; Nesheva, D.; Aneva, Z.; Petrova, A., Photoconductivity and Relaxation Dynamics in Sonochemically Synthesized Assemblies of AgBiS2 Quantum Dots. The Journal of Physical Chemistry C 2011, 115 (1), 37-46.

44. We note here that the work by Pai et al. outlines the fabrication of AgBiS2 solar cells by the spray pyrolysis of solutions comprising bismuth(III)tris(4-methylbenzodithioate), silver(I) acetate and 1-octanethiol in toluene. Importantly, the authors noted that the precursor solution being deposited was homogeneous and black in color, which is atypical for a molecular precursor of this kind. This color was produced after the addition of silver acetate and can only arise due to the precipitation of either silver sulfide nanocrystals (and residual bismuth complex) and/or silver bismuth sulfide nanocrystals. As such the deposition solution may not be considered a pure molecular precursor.

45. Hsu, W.-C.; Zhou, H.; Luo, S.; Song, T.-B.; Hsieh, Y.-T.; Duan, H.-S.; Ye, S.; Yang, W.; Hsu, C.-J.; Jiang, C.; Bob, B.; Yang, Y., Spatial Element Distribution Control in a Fully Solution-Processed Nanocrystals-Based 8.6\% Cu2ZnSn(S,Se)4 Device. ACS Nano 2014, 8 (9), 9164-9172.

46. Wei, W.; T., W. M.; Oki, G.; Tayfun, G.; K., T. T.; Yu, Z.; B., M. D., Device Characteristics of CZTSSe Thin-Film Solar Cells with 12.6\% Efficiency. Advanced Energy Materials 2014, 4 (7), 1301465.

47. Chirilă, A.; Reinhard, P.; Pianezzi, F.; Bloesch, P.; Uhl, A. R.; Fella, C.; Kranz, L.; Keller, D.; Gretener, C.; Hagendorfer, H.; Jaeger, D.; Erni, R.; Nishiwaki, S.; Buecheler, S.; Tiwari, A. N., Potassium-induced surface modification of $\mathrm{Cu}(\mathrm{In}, \mathrm{Ga}) \mathrm{Se} 2$ thin films for highefficiency solar cells. Nature Materials 2013, 12, 1107.

48. $\quad$ NIST X-ray Photoelectron Spectroscopy Database

(https://srdata.nist.gov/xps/Default.aspx).

49. Weaver, J. F.; Hoflund, G. B., Surface Characterization Study of the Thermal Decomposition of AgO. The Journal of Physical Chemistry 1994, 98 (34), 8519-8524.

50. $\quad$ https://xpssimplified.com/elements/silver.php. 
51. Hoflund, G. B.; Hazos, Z. F.; Salaita, G. N., Surface characterization study of Ag, $\mathrm{AgO}$, and $\$\{\backslash$ mathrm $\{\mathrm{Ag}\}\} \_\{2\} \backslash$ mathrm $\{\mathrm{O}\}$ \$ using $\mathrm{x}$-ray photoelectron spectroscopy and electron energy-loss spectroscopy. Physical Review B 2000, 62 (16), 11126-11133.

52. Castner, D. G.; Hinds, K.; Grainger, D. W., X-ray Photoelectron Spectroscopy Sulfur $2 p$ Study of Organic Thiol and Disulfide Binding Interactions with Gold Surfaces. Langmuir 1996, 12 (21), 5083-5086.

53. Singh, A.; Geaney, H.; Laffir, F.; Ryan, K. M., Colloidal Synthesis of Wurtzite $\mathrm{Cu} 2 \mathrm{ZnSnS} 4$ Nanorods and Their Perpendicular Assembly. Journal of the American Chemical Society 2012, 134 (6), 2910-2913.

54. van Embden, J.; Tachibana, Y., Synthesis and characterisation of famatinite copper antimony sulfide nanocrystals. Journal of Materials Chemistry 2012, 22 (23), 11466-11469. 55. Rajagopalan, N. R.; Krishnamoorthy, P.; Jayamoorthy, K.; Manikandan, S., Synthesis, Characterization, Thermal Analysis, Nucleation Kinetics and DFT Studies of Bis(thiourea) Antimony Tribromide as Potential NLO Material: Comparison of Experimental and Computational Studies. Journal of Inorganic and Organometallic Polymers and Materials 2017, 27 (5), 1457-1465.

56. Wang, X.; Li, J.; Liu, W.; Yang, S.; Zhu, C.; Chen, T., A fast chemical approach towards Sb2S3 film with a large grain size for high-performance planar heterojunction solar cells. Nanoscale 2017, 9 (10), 3386-3390.

57. Palik, E. D., Handbook of Optical Constants of Solids. Academic Press: San Diego, CA, 1998.

58. De Wolf, S.; Holovsky, J.; Moon, S.-J.; Löper, P.; Niesen, B.; Ledinsky, M.; Haug, F.-J.; Yum, J.-H.; Ballif, C., Organometallic Halide Perovskites: Sharp Optical Absorption Edge and Its Relation to Photovoltaic Performance. The Journal of Physical Chemistry Letters 2014, 5 (6), 1035-1039.

59. Aspnes, D. E.; Studna, A. A., Dielectric functions and optical parameters of Si, Ge, $\mathrm{GaP}, \mathrm{GaAs}, \mathrm{GaSb}, \mathrm{InP}, \mathrm{InAs}$, and InSb from 1.5 to $6.0 \mathrm{eV}$. Physical Review B 1983, 27 (2), 985-1009.

60. Jasieniak, J.; Califano, M.; Watkins, S. E., Size-Dependent Valence and Conduction Band-Edge Energies of Semiconductor Nanocrystals. ACS Nano 2011, 5 (7), 5888-5902.

61. Mandeep, S.; Enrico Della, G.; Taimur, A.; Sumeet, W.; Rajesh, R.; Joel van, E.; Edwin, M.; Vipul, B., Soft exfoliation of 2D SnO with size-dependent optical properties. $2 D$ Materials 2017, 4 (2), 025110.

62. The low overall on/off ratio may be attributed to the architecture of the measurement device, which has an electrode gap of $\sim 4 \mu \mathrm{m}$. This gap is approximately two orders of magnitude greater than optimal charge transport distances noted for AgBiS2 solar cells $(\sim 50$ $\mathrm{nm})$, which culminates in a high background dark current. .

63. Jasieniak, J.; MacDonald, B. I.; Watkins, S. E.; Mulvaney, P., Solution-Processed Sintered Nanocrystal Solar Cells via Layer-by-Layer Assembly. Nano Letters 2011, 11 (7), 2856-2864.

64. Gao, J.; Jeong, S.; Lin, F.; Erslev, P. T.; Semonin, O. E.; Luther, J. M.; Beard, M. C., Improvement in carrier transport properties by mild thermal annealing of $\mathrm{PbS}$ quantum dot solar cells. Applied Physics Letters 2013, 102 (4), 043506.

65. We presume this black precipitate is silver sulfide, which then dissolves to form the Ag-DTC complex due to the acidic nature of the DCTA. 